\title{
Brucella Peritonitis and Leucocytoclastic Vasculitis due to Brucella melitensis
}

\author{
Murat Dizbay ${ }^{1}$, Kenan Hizel ${ }^{1}$, Selcuk Kilic ${ }^{2}$, Ruya Mutluay ${ }^{3}$, Yavuz Ozkan ${ }^{1}$ and Tarkan Karakan ${ }^{4}$ \\ ${ }^{1}$ Department of Clinical Microbiology and Infectious Diseases; ${ }^{2}$ Refik Saydam National Hygiene Center, Department of Communicable \\ Diseases Research; ${ }^{3}$ Department of Nephrology, ${ }^{4}$ Department of Gastroenterology, Gazi University School of Medicine; Ankara, Turkey
}

\begin{abstract}
Brucellosis is a multisystemic disease that rarely leads to a fatal outcome. While reticuloendothelial system organs are mostly affected, peritonitis and posthepatitic cirrhosis are also complications of brucellosis, though they are very rare. Brucella spp. can also trigger immunological reactions. We report a case of brucellosis with peritonitis, renal failure and leucocytoclastic vasculitis caused by Brucella melitensis, which led to a fatal outcome. Brucellosis should be considered in the differential diagnosis of vasculitic diseases, especially in endemic areas.

Key-Words: Brucella melitensis, peritonitis, cirrhosis, leucocytoclastic vasculitis, cryoglobulinemia.
\end{abstract}

Brucellosis is a common multisystemic infectious disease with a variety of clinical manifestations. However, primary peritonitis due to Brucella spp. has rarely been reported; it is most commonly seen in patients with other underlying diseases, such as alcoholic cirrhosis, chronic liver disease and ascites [1]. In brucellosis, skin lesions including vasculitis, which is another unusual clinical manifestation, may occur due to immunological reactions $[2,3]$.

We report a case of brucella peritonitis that led to a fatal outcome in a patient with ascites, renal failure and leucocytoclastic vasculitis caused by Brucella melitensis.

\section{Case Report}

A 64-year-old male patient was admitted to the hospital with complaints of abdominal pain, nausea and progressivelydeveloping weakness of two months duration. There was no history of fever, alcohol consumption or hepatotoxic drug intake. An abdominal ultrasonography (USG) performed one month before for the same complaints revealed massive ascites, hepatomegaly and hypoecogenicity of the liver paranchyma; at that time, the complete blood cell count was normal, total bilirubin $4.2 \mathrm{mg} / \mathrm{dL}$, direct bilirubin $1.4 \mathrm{mg} / \mathrm{dL}$, aspartate aminotransferase (AST) $59 \mathrm{U} / \mathrm{L}$, alanine aminotransferase (ALT) $23 \mathrm{U} / \mathrm{L}$. On admission he was conscious, pale and icteric, but had no fever. His physical examination revealed diffuse epigastric tenderness and abdominal distension, ascites, bilateral pretibial edema and flapping tremors, but no organomegaly. Other physical findings were unremarkable. The patient had been diagnosed as having grade-III encephalopathy, and he was hospitalized. Laboratory findings were as follows: white blood cell (WBC) $11,700 / \mathrm{mm}^{3}$ and erythrocyte sedimentation rate (ESR) $50 \mathrm{~mm} / \mathrm{h}$, hemoglobin 15.7 $\mathrm{g} / \mathrm{dL}$, AST $78 \mathrm{U} / \mathrm{L}$, ALT $39 \mathrm{U} / \mathrm{L}$, alkaline phosphatase $256 \mathrm{U} / \mathrm{L}$, lactate dehydrogenase $(\mathrm{LDH}) 257 \mathrm{U} / \mathrm{L}$, gamma-glutamyl transferase (GGT) $88 \mathrm{U} / \mathrm{L}$, total protein $7.7 \mathrm{~g} / \mathrm{dL}$, albumin $2.9 \mathrm{~g} /$ $\underline{\mathrm{dL}, \text { total bilirubin } 4.83 \mathrm{mg} / \mathrm{dL} \text {, direct bilirubin } 1.96 \mathrm{mg} / \mathrm{dL}, \mathrm{PT} 15.6,}$ Received on 22 January 2007; revised 16 July 2007.

Address for correspondence: Dr. Murat Dizbay. Gazi University School of Medicine, Department of Clinical Microbiology and Infectious Diseases, 06510, Besevler, Ankara, Turkey. Phone: +90 3122025432 Fax: +90 312 2136333. E-mail:muratdizbay@gazi.edu.tr

The Brazilian Journal of Infectious Diseases 2007;11(4):443-444. (C) 2007 by The Brazilian Journal of Infectious Diseases and Contexto Publishing. All rights reserved. and aPTT 41.6. HBsAg was negative, anti-HBs positive ( $49 \mathrm{mIU} /$ $\mathrm{mL}$ ), HbeAg negative, anti-Hbe positive, total anti-HBc positive, HBV-DNA negative, anti-HCV and HCV-RNA negative. Smooth muscle antigen (SMA), liver-kidney microsomal antigen (LKM) and antimitochondrial antigen (AMA) were negative, but antinuclear antigen (ANA) was positive. Abdominal USG showed ascites. The peritoneal fluid was exudative; $\mathrm{WBC}$ was $1270 / \mathrm{mm}^{3}$, with lymphocyte predominance (68\%), total protein $2.9 \mathrm{~g} / \mathrm{dL}$, LDH 256 U/L. No organisms were seen on Gram staining of peritoneal fluid and there was no growth on blood agar or on eosin-methylene-blue (EMB) agar cultures. Liver biopsy could not be performed because of the patient's poor clinical condition. Upper gastrointestinal system (GIS) endoscopy revealed grade I esophageal varices, and grade II portal hypertensive gastropathy. Portal doppler ultrasonography showed that his liver was smaller $(100 \mathrm{~mm})$ than normal and the spleen was normal.

Ampicillin-sulbactam therapy was started empirically. At the end of the first week, vasculitic skin eruptions appeared most prominently on the legs. A skin biopsy revealed leucocytoclastic vasculitis. Progressive renal dysfunction, hypocomplementemia (C3:44, C4:10), positive rheumatoid factor $(27.6 \mathrm{IU} / \mathrm{mL})$, high immunoglobulin levels ( $\operatorname{IgG} 2520$, IgA 1520, IgE 469), positive P-ANCA and negative C-ANCA values supported the hypothesis of vasculitic disease.

On the fifth day of treatment, a second peritoneal fluid examination was performed, and the fluid was also cultured into an automated Bactec system. Peritoneal fluid WBC was $15 / \mathrm{mm}^{3}$ and no bacteria were seen on Gram staining; Brucella spp. was isolated from the Bactec culture. The brucella standard tube agglutination test was positive at a dilution of 1/10,240. Sulbactam-ampicillin therapy was changed to doxycycline and rifampin combined therapy. The isolate was identified as Brucella melitensis biovar 3 by conventional methods (Gram stain and growth characteristics, $\mathrm{CO}_{2}$ requirement for growth, urea hydrolysis, $\mathrm{H}_{2} \mathrm{~S}$ production, dye sensitivity, susceptibility to Tbilisi phage and agglutination with monospecific antisera. The minimum inhibitory concentration (MIC) levels to various antibiotics were determined by the E-test as rifampin $1 \mu \mathrm{g} / \mathrm{mL}$, streptomycin $0.75 \mu \mathrm{g} / \mathrm{mL}$, tetracycline $0.250 \mu \mathrm{g} / \mathrm{mL}$, ciprofloxacin $0.25 \mu \mathrm{g} / \mathrm{mL}$ and TMP-SMX $0.094 \mu \mathrm{g} / \mathrm{mL}$. Based on the antimicrobial susceptibility test results, ofloxacine was added to the therapy on the third day. However, the patient's clinical condition worsened. Disseminated intravascular 
coagulation (DIC) parameters were prothrombin time (PT) (16.4, $\uparrow)$, activated partial thromboplastin time (aPTT) $(45.3, \uparrow$ ), fibrinogen $(80 \mathrm{mg} / \mathrm{dL})$, d-dimer $(959 \mathrm{mg} / \mathrm{dL})$, direct Coombs IgG positive, platelet count low $\left(70,000 / \mathrm{mm}^{3}\right)$ and reticulocyte count normal. The results were found concordant with chronicdisseminated intravascular coagulation (DIC). Hemodialysis was applied twice because of developing renal failure. Despite treatment, his clinical condition worsened progressively and he died on the $28^{\text {th }}$ day of his hospital stay.

\section{Discussion}

Brucellosis is a common zoonotic disease with worldwide distribution, and Brucella melitensis is the most common cause. It affects many organs in the human body and sometimes it requires a multidisciplinary approach. Frequent complications include epididymitis, orchitis, abortions, hepatitis, osteomyelitis of the vertebrae, and hepatic and splenic abscesses. A high degree of awareness of brucellosis by clinicians is essential, especially in endemic areas.

Brucella melitensis was isolated from our patient's peritoneal fluid. In the literature, brucella peritonitis has been reported very rarely, and most cases are associated with cirrhosis or chronic liver disease [3-7]. Although there was no history of cirrhosis or chronic liver parenchyma disease prior to onset of symptoms, mildly-elevated liver-function tests, presence of hepatomegaly, massive ascites and hypoecogenicity on abdominal USG on first admission were thought to be related to a possible cirrhosis in our patient. However, posthepatitic cirrhosis has also been reported as a rare complication of brucellosis in the literature $[1,8]$. This same condition could have existed in this patient. Progressive regression of hepatomegaly during the one-monthhospitalization period, the detection of grade-I esophageal varices and grade-II portal hypertensive gastropathy in upper gastrointestinal endoscopy, and development of hepatic encephalopathy, led us to conclude that the patient's clinical condition was a new event, secondary to acute brucellosis infection. Negative viral and autoimmune hepatitis markers supported this hypothesis.

Direct inoculation of ascitic fluid into Bactec blood culture bottles improve the bacteriological yield in peritonitis [9]. In our patient, ascitic fluid culture gave a positive result by the Bactec method but not by conventional culture methods. Therefore, we suggest the inoculation of ascitic fluid into Bactec bottles, especially when the etiological agent is not detected by conventional-culture methods.

Skin lesions in brucellosis have been reported in 5\%-15\% of patients, and they are often nonspecific and transient [2]. The most common skin lesions are generalized erythematous rash, maculopapular rash, purpura, and subcutaneous nodules [10]. Although their relationship with brucella infection has not been well established, vasculitic lesions have been occasionally reported [2]. Yrivarren and Lopez reported three cases of cryoglobulinemia and cutaneous vasculitis in patients with brucellosis [11]. Immunological abnormalities and purpuric eruptions associated with coagulation disorders have also been reported as a consequence of brucellosis infection [2,11]. Lazcano et al. reported a case, which included mixed cryoglobulinemia with renal failure, cutaneous vasculitis and peritonitis due to $B$. melitensis [12]. They concluded that cryoglobulins can mediate and/or be responsible for all the clinical disturbances (cutaneous, renal and hepatic) observed in the patient. Membranoproliferative glomerulonephritis, intraluminal cryoglobulin deposition, moderate renal failure and nephrotic syndrome are found in patients with mixed cryoglobulinemia [11]. It is most probable that our patient developed autoimmune phenomena during infection with Brucella melitensis. Retrospectively, hypocomplementemia, increased levels of polyclonal immunoglobulins (IgG, IgA and IgE), positivity of rheumatoid factor and P-ANCA, progressive renal failure and leucocytoclastic vasculitis could be related to a type-III mixed cryoglobulinemia. However, cryoglobulin levels could not be tested in our patient. The patient's clinical condition had worsened rapidly, and he died without complete diagnostic procedures being performed.

Consequently, we believe that all the clinical abnormalities, such as peritonitis, leucocytoclastic vasculitis, and renal failure occurred as a direct consequence of brucellosis in our patient. Our case supports the hypothesis that immunological mechanisms that can lead to serious systemic complications, and even to death, can be triggered by brucellosis. Therefore, brucellosis should be considered in the differential diagnosis of vasculitic diseases, especially in endemic countries.

\section{References}

1. Ablin J., Mevorach D., Eliakim R. Brucellosis and the gastrointestinal tract: the odd couple. J Clin Gastroenterol 1997;24:25-9.

2. Milionis H., Christou L., Elisaf M. Cutaneous manifestations in brucellosis: Case report and review of the literature. Infection 2000;28:124-6.

3. Taskapan H., Oymak O., Sümerkan B., Tokgoz B. Brucella peritonitis in a patient on continuous ambulatory peritoneal dialysis with acute brucellosis. Nephron 2002;91:156-8.

4. Demirkan F., Akalin H.E., Simsek H., et al. Spontaneous peritonitis due to Brucella melitensis in a patient with cirrhosis. Eur J Clin Microbiol Infect Dis 1993;12:66-7.

5. Erbay A., Bodur H., Akinci E., et al. Spontaneous bacterial peritonitis due to Brucella melitensis. Scand J Infect Dis 2003;35:196-7.

6. Gursoy S., Baskol M., Ozbakir O., et al. Spontaneous bacterial peritonitis due to Brucella infection. Turk J Gastroenterol 2003; $14: 145-7$.

7. Halim M.A., Ayub A., Abdulkareem A., et al. Brucella peritonitis. J Infect 1993;27:169-72.

8. Williams R.K., Crossley K. Acute and chronic hepatic involvement of brucellosis. Gastroenterology 1982:83:455-8.

9. Singh N., Rihs J.D., Gayowski T., et al. Improved detection of spontaneous bacterial peritonitis with Bactec as compared with conventional culture methods. A prospective study. Diagn Microbiol Infect 1994;19:1-4.

10. Madkour M.M. Cutaneous and soft tissue brucellosis. In: Madkour MM, ed. Madkour's Brucellosis. Germany: Springer, 2001. p.193-200.

11. Yrivarren J.L., Lopez L.R. Cryoglobulinemia and cutaneous vasculitis in human brucellosis. J Clin Immunol 1987;7:471-4.

12. Lazcano I.H., Mendez L.S., Santos J.S. Mixed cryoglobulinemia with renal failure, cutaneous vasculitis and peritonitis due to $B$. melitensis. J Infect 2005;51:257-9. 